\title{
Household Inequality, Welfare, and the Setting of Trade Policy
}

\author{
Joseph Francois* \\ Hugo Rojas-Romagosa
}

Faculty of Economics, Erasmus Universiteit Rotterdam, and Tinbergen Institute.

* CEPR. 


\section{Tinbergen Institute}

The Tinbergen Institute is the institute for economic research of the Erasmus Universiteit Rotterdam, Universiteit van Amsterdam, and Vrije Universiteit Amsterdam.

Tinbergen Institute Amsterdam

Roetersstraat 31

1018 WB Amsterdam

The Netherlands

Tel.: $\quad+31(0) 205513500$

Fax: $\quad+31(0) 205513555$

Tinbergen Institute Rotterdam

Burg. Oudlaan 50

3062 PA Rotterdam

The Netherlands

Tel.: $\quad+31(0) 104088900$

Fax: $\quad+31(0) 104089031$

Please send questions and/or remarks of nonscientific nature to driessen@tinbergen.nl.

Most TI discussion papers can be downloaded at http://www.tinbergen.nl. 


\title{
Household Inequality, Welfare, and the Setting of Trade Policy
}

\author{
Joseph F. Francois \\ Tinbergen Institute (Erasmus University) and CEPR \\ Hugo Rojas-Romagosa \\ Tinbergen Institute (Erasmus University)
}

(Version 3.0)

August 2004

\begin{abstract}
We analyze general equilibrium relationships between trade policy and the household distribution of income, decomposing social welfare into real income level and variance components through Gini and Atkinson indexes. We embed these inequality-adjusted social welfare functions in a general equilibrium structure mapping from tariff protection to household inequality. This yields predictions regarding the linkages between trade protection, country characteristics and inequality in Heckscher-Ohlin and Ricardo-Viner frameworks. In addition, we can separate the efficiency and equity effects of tariffs on welfare. We then examine endogenous tariff formation when policy makers care about both equity and special interests.
\end{abstract}

Keywords: trade policy, household distribution of income, Atkinson index, Gini index, political economy

JEL classification: F13, O15, D31, D72

\section{Introduction}

There has been widespread interest in the policy community in the distributional effects of trade liberalization. Recent anti-globalization rhetoric has focused on the potential negative impact of trade and outsourcing for unskilled wages in developed countries, while arguing that it may also hurt workers in poor countries. On the other hand, many economists regard trade liberalization as an instrument for increasing growth, but are less certain about the distributional effects of increased openness. 
Driven in large part by continued policy interest, the relationship between trade openness and wages has also been an active topic of debate in the research community. ${ }^{1}$ However, this literature focuses on the functional distribution of income, with less emphasis on household distribution issues. ${ }^{2}$ The current literature has stressed theoretical linkages based on the Stolper-Samuelson theorem. In this context, tariff reductions in poor labor-abundant countries are expected to increase the real income of workers and hurt capital owners (or skilled labor). In developed countries the opposite effect is expected. The empirical evidence remains mixed and somewhat contradictory.

In this paper, we follow Bourguignon and Morrisson $(1989,1990)$ and Spilimbergo et al. (1999) and use an ownership matrix that allows us to move from functional to household income. We then obtain a general function of the personal income distribution in terms of endowments, tariffs and the ownership structure. Using this analytical framework, we analyze the impact of trade and tariffs on the household distribution of income in general equilibrium.

Treating equity issues as relevant, we work with Sen-type social welfare functions (Sen, 1974) and embed inequality indexes in social welfare indexes. In particular, we work with the widely used Gini coefficient and with the Atkinson family of inequality indexes (Atkinson, 1970), although other indexes may be employed. Using this framework we are able to decompose the general equilibrium import protection effects into real income level and dispersion changes.

The efficiency properties of tariffs are well developed in the literature. What we highlight here is how distributional aspects of social welfare related to import protection may be examined alongside efficiency aspects. For government, this is manifested not only in special interest politics, but also through the direct impact of inequality on a government's objective function. We find that equity considerations may serve to counter lobbying interests in both capital-rich and capital-poor countries, though with opposite marginal impact on the final policy outcome. Although we focus our attention only on import tariffs, the main message that follows from this approach can be applied in a more general context of trade policy instruments. The precise distributional and efficiency components may change, but in essence the trade-off and interrelation between both economic outcomes is still present.

The paper is organized as follows. Section 2 develops a formal representation of social

\footnotetext{
${ }^{1}$ Comprehensive surveys are provided by Richardson (1995), Cline (1997) and Feenstra and Hanson (2004).

${ }^{2}$ Recent papers include Edwards (1997), Higgins and Williamson (1999), Barro (2000) and Spilimbergo et al. (2001).
} 
welfare inclusive of income inequality. In Section 3, we embed this social welfare function into a general equilibrium trade model. We also develop the equilibrium representation of inequality, based on the general equilibrium system fundamentals. Section 4 then explores linkages between trade policy, inequality, and welfare. It also examines theoretical linkages between country size, development, policy, and inequality. In Section 5, we explore the implications of the addition of inequality to the social welfare component of a government's objective function for political support function models of tariff formation. We conclude in Section 6 .

\section{Defining social welfare with respect to inequality}

Our goal in this section is to develop a functional linkage between inequality and aggregate (social) welfare. This will then be integrated in the next section into a dual general equilibrium trade model. A critical condition for inequality to have a meaningful link to aggregate (social) welfare is that the utility function be strictly concave with respect to income. Additionally, for tractability we prefer to work with a social welfare function that is symmetric and additively separable in individual incomes.

The existence of social welfare functions depends crucially on the possibility to compare interpersonal utility levels. One such possibility is offered by the 'veil of ignorance' approach first proposed by Harsanyi $(1953,1955)$ and further developed by Rawls (1971), where we rank different individual situations not knowing which would be the actual situation. As stated by Sen (1997) this interpersonal comparison can be defined as those situations where we make judgements of the type:

"I would prefer to be person A rather than person B in this situation" and "while we do not really have the opportunity (or perhaps the misfortune, as the case may be) of in fact becoming A or B, we can think quite systematically about such a choice, and indeed we seem to make such comparisons frequently".

Because GDP per capita is the most common indicator of social welfare, the "veil of ignorance' approach supports the use of an inequality measure to complement GDP per capita comparisons. If we do not know which individual household we are in a specific country, then the expected utility becomes a function of mean income and the personal distribution of income. How we evaluate the probability of receiving any given income is then determined by the functional representation of the utility function and more specifically by the degree 
of concavity of this function. In this context, a natural extension of cross-country welfare comparisons is to complement GDP per capita levels with some measure of inequality. ${ }^{3}$

Under the social welfare approach to income distribution measurement, inequality is associated with variance in the distribution of income. This raises two measurement problems. The first is that we cannot generally rely on first moment-based indicators. The second is that even though the concepts of Lorenz-dominance and General Lorenz-dominance (Shorrocks, 1983) are accepted as ways to impartially rank two different distributions ${ }^{4}$, in many cases the Lorenz-curves intersect at least once, so that we obtain incomplete ranking of distributions. To solve both these problems, inequality indexes are usually used to rank distributions in indeterminate cases and to provide a summary variable that can be used in empirical models. While the most commonly used is the Gini coefficient, most inequality measures are implicitly based on a social welfare function (Dalton, 1920; Kolm, 1969; Atkinson,1970). As such, there is no perfect index, and any index has built in social preferences.

In this paper, we employ two representations of household utility and social welfare. Both reflect Sen's (1974) preferred definition of social welfare as:

$$
S W=\bar{y}(1-I)
$$

where $S W$ is the social welfare, $\bar{y}$ is mean income, and $I$ is an index of inequality.

Starting with CRRA preferences yields the well-known Atkinson inequality index directly as a natural metric for a mapping from income distribution to social welfare (see Atkinson 1970). In this sense, Atkinson's index fits naturally into Sen's proposed social welfare function.

Sen actually offered equation (1) as defined with respect to the Gini coefficient. In this case, the social welfare function is axiomatic, in that we do not have an obvious mapping -through aggregation- from individual preferences to an aggregate social welfare function. This follows because the social welfare function is then rank sensitive. We work with both the Atkinson index and Gini coefficient in this paper.

\subsection{The Atkinson index-based social welfare function}

Formally, we define a composite consumer good over the range of all consumption goods, which follows from a linear homothetic aggregation function. As such, cost minimization yields a composite consumer price index. This is defined over all consumer prices $p_{c}$.

\footnotetext{
${ }^{3}$ This approach was formally treated by Sen (1976).

${ }^{4}$ See Lambert (1993) for details.
} 


$$
p_{c}=f(p)
$$

Household utility $u^{h}$ is defined as a function of household consumption of the composite consumer good $c^{h}$ :

$$
u^{h}=\psi\left(c^{h}\right)
$$

We next map aggregate individual utility to aggregate welfare $\phi$, which is defined as the sum of household utility,

$$
\phi=\sum_{h} u^{h}
$$

while aggregate consumption $c$ is the sum of household consumption.

$$
c=\sum_{h} c^{h}
$$

We will assume that the function $\psi$ is CRRA: ${ }^{5}$

$$
\psi\left(c^{h}\right)=\left\{\begin{array}{cc}
\frac{\left(c^{h}\right)^{1-\theta}}{1-\theta} & \text { if } \theta \neq 1 \\
\ln c^{h} & \text { if } \theta=1
\end{array}\right.
$$

In general, we assume that $\theta>0$, and in this paper we focus on the case where $\theta \neq 1$. $^{6}$ We employ a simple linear transformation, and are then able to define a social welfare index in per-capita terms.

$$
S W_{A}=\frac{\phi}{n(1-\phi)}=\frac{1}{n} \sum_{h}\left(c^{h}\right)^{1-\theta}
$$

Simple manipulation then yields social welfare as a function of per-capita income $\bar{y}$, consumer prices, and income equality.

$$
S W_{A}=\left(\frac{\bar{y}}{p_{c}}\right)^{1-\theta} E_{A}^{1-\theta}
$$

With some further manipulation, our equality measure $E_{A}$ can be mapped directly to the Atkinson index of income inequality, yielding a Sen-type social welfare function. In particular, taking the definition of the Atkinson index (Atkinson, 1970), we have the following relationships between the Atkinson index $I_{A}, E_{A}$, and social welfare.

\footnotetext{
${ }^{5}$ In the present context, constant relative inequality aversion (CRIA) is a better label and acronym.

${ }^{6}$ One gets the same basic results with log preferences. Estimates in the macro literature are that $\theta$ is less than 1.
} 


$$
\begin{gathered}
I_{A}=1-\left(\frac{1}{n} \sum_{h}\left(\frac{y^{h}}{\bar{y}}\right)^{1-\theta}\right)^{\frac{1}{1-\theta}}=1-E_{A} \\
S W_{A}=\left[\left(\frac{\bar{y}}{p_{c}}\right)\left(1-I_{A}\right)\right]^{1-\theta}
\end{gathered}
$$

Note that as $\theta \rightarrow 0$ only average income matters, rather than income inequality. Alternatively, when $\theta \rightarrow \infty$, then $S W_{A}=\min \left(y^{h}\right)$ and we have the extreme Rawlsian maximin social welfare function, were the income level of the poorest individual is the only relevant variable and average income is unimportant. Moreover, for a given distribution (measured as shares of total income) we have declining marginal utility of income.

\subsection{The Gini index-based social welfare function}

The Gini coefficient is defined as twice the area between the Lorenz curve and the 45-degree line. As such, $(1-G)$ is then twice the area below the Lorenz curve. Formally, this index is defined as follows:

$$
\begin{gathered}
I_{G}=1+\frac{1}{n}-\frac{2}{n^{2} \bar{y}}\left(y^{1}+2 y^{2}+\ldots+n y^{n}\right)=1+\frac{1}{n}-\left[\left(\frac{2}{n^{2}} \sum_{h} \frac{h y^{h}}{\bar{y}}\right)\right] \\
S W_{G}=\left[\left(\frac{\bar{y}}{p_{c}}\right)\left(1-I_{G}\right)\right]
\end{gathered}
$$

where we have arranged households so that $y^{1} \geq y^{2} \geq \ldots \geq y^{n}$. Unlike the Atkinsonbased social welfare function, the Gini-based social welfare function embodies asymmetry not on specific individuals, but rather on relative income rankings. This ranking provides the concavity of the utility function with respect to income. The higher the income in the ranking, the less social weight it has. At the same time, equation (12) is linear in average income. As such, $S W_{G}$ is relatively more sensitive to mean income than $S W_{A}$ and less sensitive to inequality.

\section{Inequality and trade in general equilibrium}

To explore the interaction between production, trade and trade policy, and inequality, we work with a modified dual representation of trade in general equilibrium (Dixit and Norman, 1980). To do so, we first adopt the following additional set of assumptions:

- Rational behavior by households and firms. 
- Complete and perfectly competitive markets.

- Convex technology, with neoclassical production functions.

- Goods are tradable and factors are not.

- Every household has the same neoclassical technology for producing the composite consumption good.

Given these assumptions, we are able to define the core general equilibrium system for demand and production in terms of expenditure and revenue functions, with expenditure defined in terms of the composite consumption good. Social welfare then follows as a set of side equations from the core general equilibrium system.

\subsection{The core general equilibrium system}

Because we assume that all households have the same consumption technology defined with respect to the composite consumption good, we can drop the household index from consumption and represent aggregate expenditure as a function of aggregate consumption and prices:

$$
e(p, c)=c \cdot f(p)
$$

On the production side, we assume standard neoclassical production functions with constant returns to scale: $x_{i}=g_{i}\left(v_{i j}\right)$, where $g_{i}(\cdot)$ is the production function for good $i$ and $v_{j i}$ is the use of factor $j$ in the production of good $i$. Defining unit input coefficients as $a_{j i}$ we also obtain: $1 \leq g_{i}\left(a_{j i}\right)$. Endowment constraints are then $\sum a_{j i} x_{i} \leq \bar{v}_{j}$. From these conditions, we can define the economy-wide revenue function with respect to goods prices and endowments. This is represented in equation (14).

$$
r(p, v)=\max _{x_{i}, a_{j i}}\left\{\sum_{i} p_{i} x_{i} \mid \sum_{i} a_{j i} x_{i} \leq \bar{v}_{j} \text { and } 1 \leq g_{i}\left(a_{j i}\right) \forall i, j\right\}
$$

From the envelope theorem and the properties of the revenue function $r$, factor incomes and goods production can be expressed in terms of the value of the partial derivatives of the revenue function, evaluated at the equilibrium set of prices:

$$
\begin{array}{ll}
\frac{\partial r(p, v)}{\partial v_{j}}=w_{j}=w_{j}(p, v) & \forall j \\
\frac{\partial r(p, v)}{\partial p_{i}} & =x_{i}=x_{i}(p, v) \quad \forall i
\end{array}
$$


Taking equations (15) and (16) in conjunction with equations (13) and (14), we can write the general equilibrium system for production, consumption, and trade as follows: ${ }^{7}$

$$
\begin{aligned}
c^{h} f(p) & =\left(\sum_{j} w_{j}(p, v) \cdot v_{j}^{h}\right)+\omega_{\tau}^{h} \tau m \quad \forall h \\
m & =\sum_{h} c^{h} \cdot f(p)-x(p, v) \\
e(p, c) & =\sum_{h}\left[\left(\sum_{j} w_{j}(p, v) \cdot v_{j}^{h}\right)+\omega_{\tau}^{h} \tau m\right] \\
p & =P^{*}+\tau=1+\tau
\end{aligned}
$$

In equations (17) - (20), we have assumed the home country imposes a tariff of $\tau$ on imports from the rest of the world, while world prices are normalized to one. In addition, $\omega_{t}^{h}$ is the household share of the tariff revenue and $v_{j}^{h}$ is the household ownership share of factor $j$. In the first equation, household consumption is equal to the household budget. Equation (18) defines imports on which tariff revenue is generated and equation (19) sets economy wide expenditure equal to national income. Together, the system of four equations has an equally dimensioned set of unknowns: $c^{h}, m, e$ and $p$.

\subsection{Household inequality}

As explained earlier, the recent literature on trade and the distribution of income has focused on the functional distribution of income. The functional distribution of income is also an important building block here for the representation of the household distribution of income. In equation (21) we define factor incomes $s$, which follow directly from the endowment stock and the properties of the revenue function.

$$
s_{j}=r_{v j}(p, v) \cdot v_{j}=w_{j} v_{j}
$$

Thus, the functional distribution of income is a function of equilibrium prices, preferences, the production technology and the endowment set. In reduced form, the functional distribution of income $F(s)$ is then an artefact of the equilibrium matching of preference and the technology set, given our endowment vector.

$$
F(s)=F(p, v)
$$

\footnotetext{
${ }^{7} \mathrm{~A}$ two-country general equilibrium system can readily be formalized using the same framework.
} 
Using factor incomes $w_{j}$ and the household ownership share of production factors, $\omega_{j}^{h}$ we can readily obtain household income. In addition, we include the assignment of import tariff revenue, again represented by a household share parameter. Equation (23) presents the basic definition of household income in terms of its primary components.

$$
\begin{aligned}
y^{h} & =\left(\sum_{j} w_{j} \cdot v_{j} \cdot \omega_{j}^{h}\right)+\omega_{\tau}^{h} \tau m \\
c^{h} & =\frac{y^{h}}{p_{c}}
\end{aligned}
$$

where $1 \geq \omega^{h} \geq 0$ and $\sum \omega_{j}^{h}=\sum \omega_{\tau}^{h}=1$. In reduced form, the personal distribution of income $F(y)$ is a consequence of the elements affecting the functional distribution and the $h \times j$ ownership matrix of coefficients $\omega_{j}^{h}$, represented by $\Omega$ :

$$
F(y)=F(p, v, \Omega)
$$

Note that social welfare is ultimately a function of the ownership matrix in the economy, while the impact of trade policy will then depend on the interaction of the underlying economic structure and the ownership matrix.

\subsection{Inequality indexes with system fundamentals}

We can write our social metrics of the distribution of income -the Atkinson and Gini indexesin terms of system fundamentals. Making a substitution from (23) into (9) and (11), we obtain the following equations:

$$
\begin{aligned}
& I_{A}=1-\left\{\frac{1}{n} \sum_{h}\left[\frac{n\left(\sum_{j} w_{j} v_{j} \omega_{j}^{h}\right)+n \omega_{\tau}^{h} \tau m}{y}\right]^{1-\theta}\right\}^{\frac{1}{1-\theta}} \\
& I_{A}=1-\left\{n^{-\theta} \sum_{h}\left[n^{-1}+\sum_{j} \beta_{j}\left(\omega_{j}^{h}-n^{-1}\right)\right]^{1-\theta}\right\}^{\frac{1}{1-\theta}} \\
& I_{G}=1+\frac{1}{n}-\frac{2}{n^{2}} \sum_{h} h\left[\frac{n\left(\sum_{j} w_{j} v_{j} \omega_{j}^{h}\right)+n \omega_{\tau}^{h} \tau m}{y}\right] \\
& I_{G}=1+\frac{1}{n}-\frac{2}{n} \sum_{h} h\left[n^{-1}+\sum_{j} \beta_{j}\left(\omega_{j}^{h}-n^{-1}\right)\right]
\end{aligned}
$$


where $\beta_{j}=\frac{w_{j} v_{j}}{y}$ represents the national income share of factor and $\sum_{j} \beta_{j}+\frac{\tau m}{y}=1$. In what follows, we apply the additional normalization that each household receives an equal share of the tariff revenues, so that $\omega_{\tau}^{h}=n^{-1} .8$

The ratio of the household's income to per capita income, which accounts for income dispersion, is given by the sum of the differences between the actual ownership share of factors and equal shares for each household. From equations (26) and (27), we can make a substitution back into equations (10) and (12), yielding social welfare itself as a function of system fundamentals.

$$
\begin{aligned}
S W_{A} & =\left[\frac{\bar{y}}{p_{c}}\left(1-I_{A}\right)\right]^{1-\theta} \\
S W_{A} & =\left(\frac{\bar{y}}{p_{c}}\right)^{1-\theta} n^{-\theta} \sum_{h}\left[n^{-1}+\sum_{j} \beta_{j}\left(\omega_{j}^{h}-n^{-1}\right)\right]^{1-\theta} \\
S W_{G} & =\frac{\bar{y}}{p_{c}}\left(1-I_{G}\right) \\
S W_{G} & =\left(\frac{\bar{y}}{p_{c}}\right)\left\{\frac{2}{n} \sum_{h} h\left[n^{-1}+\sum_{j} \beta_{j}\left(\omega_{j}^{h}-n^{-1}\right)\right]-n^{-1}\right\}
\end{aligned}
$$

\section{Trade policy, distribution, and welfare}

\subsection{Generalized effects}

From equations (28) and (29) above, social welfare is a function of the first two moments of the household distribution of income. This is especially obvious with the Atkinson index, as it is actually the weighted variance of income, with inverse income weights, that provides the variance component of the social welfare function. ${ }^{9}$ Because the contributions of the mean and variance components of income to social welfare are separable in equations (28) and (29), we can decompose the impact of trade policy as well into its impact on per-capita income (an efficiency effect), and its impact on the variance of income (a distributional effect). Together, they determine the overall social welfare impact. Formally, differentiating equations (28) and (29) with respect to tariffs, we obtain the following equations:

\footnotetext{
${ }^{8}$ The distributional impact of tariff revenues can be substantial. This is the emphasis of the paper by Galor (1994), which includes tariffs in his general equilibrium Overlapping-Generations model.

${ }^{9}$ While the functional form is different, the social welfare function underlying other income distribution indexes yields a similar result, though with different weights in the variance component of the welfare function. The CRRA function yields a particularly clear and parsimonious reduced form.
} 


$$
\begin{aligned}
\frac{\partial S W_{A}}{\partial \tau}= & (1-\theta)\left[\frac{\bar{y}}{p_{c}}\left(1-I_{A}\right)\right]^{-\theta}\left(1-I_{A}\right)^{1-\theta}\left(\frac{\partial \bar{y}}{\partial \tau}-\frac{\partial p_{c}}{\partial \tau} \frac{\bar{y}}{p_{c}^{2}}\right) \\
& -(1-\theta)\left(\frac{\bar{y}}{p_{c}}\right)^{1-\theta} I_{A}^{-\theta} \frac{\partial I_{A}}{\partial \tau} \\
\frac{\partial S W_{G}}{\partial \tau}= & \left(1-I_{G}\right)\left[\frac{\partial \bar{y}}{\partial \tau}-\frac{\partial p_{c}}{\partial \tau} \frac{\bar{y}}{p_{c}^{2}}\right]-\left(\frac{\bar{y}}{p_{c}}\right) \frac{\partial I_{G}}{\partial \tau}
\end{aligned}
$$

How do we interpret equations (30) and (31)? The efficiency component is well known (see for example Dixit and Norman, 1980), and is shown here in equation (32). Basically, the impact of the tariff on per-capita income will depend on the combination of terms-of-trade and allocation effects (the first set of terms in square brackets in equation (32)), and tariff revenue (the second set of terms).

$$
\frac{\partial \bar{y}}{\partial \tau}=\frac{1}{n} \sum_{h} \frac{\partial y^{h}}{\partial \tau}=\frac{1}{n}\left[m\left(1-\frac{\partial p}{\partial \tau}\right)+\tau \frac{\partial m}{\partial \tau}\right]
$$

For a small country, negative allocation effects outweigh the terms-of-trade effects, so that the impact of the tariff on mean income is strictly negative. Also, for the small country, the impact on the cost of living will be to raise prices. As such, the real mean-income effect will be strictly negative for a small country. With a large country, the combined income and cost-of-living effect, or in other words the real income effect of the tariff change as represented by the term in square brackets in the equations (30) and (31) may be positive or negative depending on the magnitude of terms-of-trade effects.

The impact on household income distribution, the other part of equations (30) and (31), follows from differentiation of equations (26) and (27). This is shown below:

$$
\begin{aligned}
\frac{\partial I_{A}}{\partial \tau}= & -n^{\frac{-\theta}{1-\theta}}\left\{\sum_{h}\left[\sum_{j} \beta_{j}\left(\omega_{j}^{h}-n^{-1}\right)+n^{-1}\right]^{1-\theta}\right\}^{\frac{\theta}{1-\theta}} \\
& \sum_{h}\left\{\left[\sum_{j} \beta_{j}\left(\omega_{j}^{h}-n^{-1}\right)+n^{-1}\right]^{-\theta}\left[\sum_{j} \frac{\partial \beta_{j}}{\partial \tau}\left(\omega_{j}^{h}-n^{-1}\right)\right]\right\} \\
\frac{\partial I_{G}}{\partial \tau}= & -\frac{2}{n} \sum_{h} h\left[\sum_{j} \frac{\partial \beta_{j}}{\partial \tau}\left(\omega_{j}^{h}-n^{-1}\right)\right]
\end{aligned}
$$

Note that we also have an inverse income weighting, by a factor of $\theta$, in equation (33) applied to induced changes in income. The weighting of induced changes in income for the Gini index depends on the ranking of individual households on the relative income scale. 
In both cases, the changes in income in turn depend on Stolper-Samuelson derivatives, and induced price changes that follow from tariff changes. This is expressed in equation (35), where the term $\frac{\partial \beta_{j}}{\partial \tau}$ depends on system fundamentals and Stolper-Samuelson relationships.

$$
\frac{\partial \beta_{j}}{\partial \tau}=\frac{\partial w_{j}}{\partial p} \frac{\partial p}{\partial \tau} \frac{v_{j}}{y}-\frac{\partial y}{\partial \tau} \frac{w_{j} v_{j}}{y^{2}}
$$

We can also represent the relationship in elasticity terms: $\varepsilon_{\beta_{j}, \tau}=\varepsilon_{w_{j}, p} \varepsilon_{p, \tau}-\varepsilon_{y, \tau}$.

\subsection{Heckscher-Ohlin inequality effects}

Assuming that all households hold a claim on one unit of labour, we can apply equations (33) and (34) to a two-factor, two-good Heckscher-Ohlin model. In this framework, equations (36) and (37) determine the impact of tariff changes on household inequality.

$$
\begin{aligned}
\frac{\partial I_{A}}{\partial \tau}= & -n^{\frac{-\theta}{1-\theta}}\left\{\sum_{h}\left[\beta_{k}\left(\omega_{k}^{h}-n^{-1}\right)+n^{-1}\right]^{1-\theta}\right\}^{\frac{\theta}{1-\theta}} \\
& \sum_{h}\left\{\left[\beta_{k}\left(\omega_{k}^{h}-n^{-1}\right)+n^{-1}\right]^{-\theta}\left[\frac{\partial \beta_{k}}{\partial \tau}\left(\omega_{k}^{h}-n^{-1}\right)\right]\right\} \\
\frac{\partial I_{G}}{\partial \tau}= & -\frac{2}{n} \sum_{h} h\left[\frac{\partial \beta_{k}}{\partial \tau}\left(\omega_{k}^{h}-n^{-1}\right)\right]
\end{aligned}
$$

Inequality is purely a function of the allocation of capital in this model. At the same time, the impact of the tariff is then a function of which sector is protected. If protection leads to an increase in wages and a drop in capital income, inequality is reduced. Alternatively, if capital income is protected, we will see a rise in inequality.

The social welfare effect, however, will depend on the trade-off between real income effects following from import protection, and the impact on inequality. In other words, the trade-off between equity and efficiency. From equations (30) and (31), this is ultimately a function of the degree of inequality aversion, combined with the structural features of the economy and its market power on world markets. For a small country, real income effects will be strictly negative, while inequality effects may be positive or negative, depending on the relative endowment structure of the economy. For a large country, it is possible for both effects to work in the same direction. However, in this case, note that positive terms-of-trade gains will slow any rise (or slow any fall) in capital income shares, from equation (35). This in turn means that terms of trade effects will tend to mitigate the inequality effects of protection.

On the basis of equation (35), (36) and (37), we can summarize our discussion above with the following observations about import protection and inequality in the 2x2 Heckscher-Ohlin 
model.

Observation 1 In a small labour-abundant Heckscher-Ohlin economy where the poor receive only or mostly labour income, and where the mean real-income effects of import protection are negative, the effect of import protection on welfare through mean income is magnified by the impact through inequality. Because of this magnification effect, net effects remain unambiguous and negative.

Observation 2 In a small, capital-abundant Heckscher-Ohlin economy, where the poor receive only or mostly labour income, and where the mean real-income effects of import protection are negative, the effect of import protection on welfare through mean income is at least partially offset by the impact through inequality. Hence the net welfare effect is ambiguous. It depends on the specification and parameterization of the underlying social welfare function.

Observation 3 The impact of protection on inequality as measured by the Atkinson and Gini indexes will be weaker, in a Heckscher-Ohlin economy, for large countries. This is because of terms of trade effects from equation (35), which will dampen the goods-price to factor-price transmission mechanisms at play.

Observation 1 flags a magnification effect, linking efficiency and inequality effects, in labour abundant economies. In contrast, we instead have an offsetting effect in capitalabundant economies, as noted in Observation 2. Observation 3 follows because our tariff analytics are driven by the transmission of tariff changes into price changes, and these are weaker in larger economies. These smaller internal price effects mean smaller inequality effects.

\subsection{Inequality effects in the $2 \times 3$ Ricardo-Viner model}

Next, consider the specific factors model. We can make a similar manipulation of equations (33) and (34), like that yielding equations (36) and (37), for the standard 2-good, 3-factor model. This yields equations (38) and (39). Again, if we assume that inequality follows from the ownership pattern of (specific) capital, then in this case a shift in income shares through protection from more to less concentrated factors (in terms of the concentration of factor ownership) yields a reduction in inequality. The same points then follow, as before, with regard to country size and inequality effects in the Heckscher-Ohlin model. Otherwise, the impact of protection on inequality depends on the pattern of relative wage and ownership effects. 


$$
\begin{aligned}
\frac{\partial I_{A}}{\partial \tau}= & -n^{\frac{-\theta}{1-\theta}}\left\{\sum_{h}\left[\beta_{k 1}\left(\omega_{k 1}^{h}-\frac{1}{n}\right)+\beta_{k 2}\left(\omega_{k 2}^{h}-\frac{1}{n}\right)+\frac{1}{n}\right]^{1-\theta}\right\}^{\frac{\theta}{1-\theta}} \\
& \sum_{h}\left\{\left[\beta_{k 1}\left(\omega_{k 1}^{h}-\frac{1}{n}\right)+\beta_{k 2}\left(\omega_{k 2}^{h}-\frac{1}{n}\right)+\frac{1}{n}\right]^{-\theta}\right. \\
& {\left.\left[\frac{\partial \beta_{k 1}}{\partial \tau}\left(\omega_{k 1}^{h}-\frac{1}{n}\right)+\frac{\partial \beta_{k 2}}{\partial \tau}\left(\omega_{k 2}^{h}-\frac{1}{n}\right)\right]\right\} } \\
\frac{\partial I_{G}}{\partial \tau}= & -\frac{2}{n} \sum_{h} h\left[\frac{\partial \beta_{k 1}}{\partial \tau}\left(\omega_{k 1}^{h}-n^{-1}\right)+\frac{\partial \beta_{k 2}}{\partial \tau}\left(\omega_{k 2}^{h}-n^{-1}\right)\right]
\end{aligned}
$$

We can summarize our results with respect to the Ricardo-Viner model as follows:

Observation 4 In a small Ricardo-Viner country, where any income effects from tariffs will be negative, protection may still be welfare improving if the induced change in inequality is large enough. This depends on the assumed functional form and parameterization of the social welfare function. If inequality is not improved, then the worsening inequality magnifies the negative efficiency effects.

Observation 5 Unlike the Heckscher-Ohlin model, the impact of protection on inequality as measured by the Gini or Atkinson index is ambiguous in the Ricardo-Viner model when capital ownership patterns are the source of inequality. This is because the degree of concentration of specific-factor ownership (the weights applies in equations (38) and (39) to the induced changes in the specific-factor share of income) may vary between the two sectors, and because the impact on capital income will have opposite sign depending on the sector protected.

This last observation associates the impact of protection on inequality to differences in ownership patterns for specific factors. If the ownership of the import-competing specific factor is sufficiently less concentrated than that for the export-sector, import protection will reduce inequality. However, if capital in the import-competing sector has relatively concentrated ownership, it will make the situation worse. For example, in a developing country where the poor have labour and land, and the rich labour and capital, protection will make the concentration of income worse, assuming the sector using capital is an importcompeting sector. On the other hand, if ownership of land is very highly concentrated relative to capital, import protection may improve the distribution of income. 


\section{The Setting of Trade Policy}

In this section, we examine the impact of inequality issues on the determination of import protection in an endogenous tariff model. We focus on the Heckscher-Ohlin model, where we obtain unambiguous results with respect to the impact of inequality considerations, in the region of a political equilibrium, on the observed tariff rate. We also discuss, briefly, the meaning of our results for endogenous tariff formation in a specific-factors model.

\subsection{Capital rents}

In our $2 \times 2$ Hecksher-Ohlin economy, we now assume consumers can be divided between workers and investors. The latter differentiate themselves by earning capital rents in addition to their labor earnings. Moreover, we assume that both groups are internally homogeneous and index them by $h=l, k$. Thus, we have $n_{k}$ investors and $n_{l}$ workers, each with real consumption defined as:

$$
\begin{aligned}
c^{l} & =\frac{w_{l}+\omega_{\tau}^{l} \tau m}{f(p)} \\
c^{k} & =\frac{w_{l}+w_{k} n_{k}^{-1}+\omega_{\tau}^{k} \tau m}{f(p)}
\end{aligned}
$$

Assuming a CRRA utility function as in equation (6) with $\theta \neq 1$, we get:

$$
\begin{aligned}
u^{l} & =\frac{1}{1-\theta}\left(\frac{w_{l}+\omega_{\tau}^{l} \tau m}{f(p)}\right)^{1-\theta} \\
u^{k} & =\frac{1}{1-\theta}\left(\frac{w_{l}+w_{k} n_{k}^{-1}+\omega_{\tau}^{k} \tau m}{f(p)}\right)^{1-\theta}
\end{aligned}
$$

Introducing a tariff change, the utility of each representative consumer is modified according to equations (44) and (45). We assume that each household is entitled to the same share of tariff revenue: $\omega_{\tau}^{l}=\omega_{\tau}^{k}=n^{-1}$.

$$
\begin{aligned}
\frac{\partial u^{l}}{\partial \tau}= & \left(\frac{w_{l}+\tau m n^{-1}}{f(p)}\right)^{-\theta} \frac{1}{f(p)} \\
& {\left[\frac{\partial w_{l}}{\partial \tau}+m n^{-1}+\frac{\partial m}{\partial \tau} \tau n^{-1}-\frac{\left(w_{l}+\tau m n^{-1}\right)}{f(p)} \frac{\partial f(p)}{\partial \tau}\right] } \\
\frac{\partial u^{k}}{\partial \tau}= & \left(\frac{w_{l}+w_{k} n_{k}^{-1}+\tau m n^{-1}}{f(p)}\right)^{-\theta} \frac{1}{f(p)} \\
& {\left[\frac{\partial w_{l}}{\partial \tau}+\frac{\partial w_{k}}{\partial \tau} n_{k}^{-1}+m n^{-1}+\frac{\partial m}{\partial \tau} \tau n^{-1}-\frac{\left(w_{l}+w_{k} n_{k}^{-1}+\tau m n^{-1}\right)}{f(p)} \frac{\partial f(p)}{\partial \tau}\right] }
\end{aligned}
$$




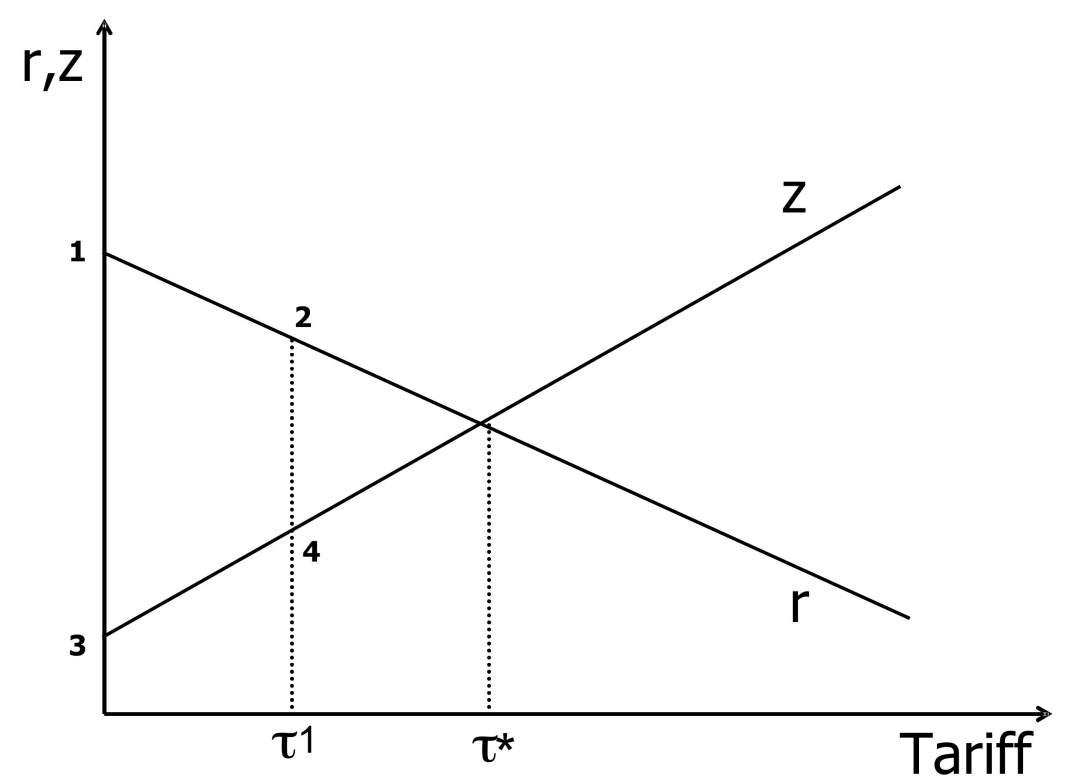

Figure 1: Investor rents with respect to tariff levels

In a small open labor-abundant economy, we know from the Stolper-Samuelson theorem that: $\frac{\partial w_{l}}{\partial \tau}<0, \frac{\partial w_{k}}{\partial \tau}>0$ and by construction $\frac{\partial f(p)}{\partial \tau}>0$. Therefore, the workers are hurt by the tariff, both because of the efficiency and the distributional impact of the tariff. We obtain the optimum tariff for each group by equating (44) and (45) to zero. The workers' optimum tariff is zero, since tariffs reduce their share of total income (itself decreasing) and increase prices. For the investors, equation (46) shows the first order equilibrium condition.

$$
\begin{aligned}
\frac{\partial w_{k}}{\partial \tau} n_{k}^{-1}+\left(n^{-1} m+\frac{\partial m}{\partial \tau} \tau n^{-1}-\frac{\tau m n^{-1}}{f(p)}\right) & =\frac{\left(w_{l}+w_{k} n_{k}^{-1}\right)}{f(p)} \frac{\partial f(p)}{\partial \tau}-\frac{\partial w_{l}}{\partial \tau} \\
r & =z
\end{aligned}
$$

The left hand side term represents investor tariff gains $(r)$ that compensate for the tariff cost $(z)$, which are shown in the right hand side. Note that these costs are the same as the net welfare effect (folding in tariff revenues) on workers. While $r$ is a combination of increased capital earnings and the tariff revenue, $z$ includes the rise in the consumer goods price and the reduction in labor earnings. Moreover, both components are not monotonically related to tariffs. In particular, $\frac{\partial r}{\partial \tau}<0$ and $\frac{\partial z}{\partial \tau}>0$. We depict the investors' optimal tariff in Figure 1 as $\tau=\tau *$.

For any given tariff, the net rents are equivalent to the area between both curves. In the 
figure, this is equal to the trapezoid connected by points 1, 2, 3 and 4 , when $\tau=\tau^{1}$. From equation (46) the optimum tariff $\tau^{*}$ for investors is the intersection of $r$ and $z$. Beyond this point, the increase in capital rents is offset by the increase in prices and the decrease in wage earnings.

As a group, investor rents $R$ are given by:

$$
R(\tau)=n_{k} \int(r-z) d \tau
$$

where $r$ and $z$ are defined in equation (46). Moreover, $R(\tau)>0, \frac{\partial R(\tau)}{\partial \tau}>0$, and $\frac{\partial^{2} R(\tau)}{\partial \tau^{2}}<0$ over the relevant range.

\subsection{The government's maximization problem}

At this point, we could invoke a variety of different political economy models to generate political underpinnings for the setting of an equilibrium tariff in the political marketplace. These models have been extensively analyzed in the recent literature ${ }^{10}$, and following Helpman (1995) we note that many of these can be represented, in reduced form, by the now standard political support function.

Direct democracy is a rare political mechanism and generally public policies are decided by representative governments that balance conflicting interests. From Hillman (1989) we know that when one of the factors is sufficiently concentrated across only a few households, these individuals can organize to form pressure groups and overcome the free-rider problem. In such cases, Grossman and Helpman (2002) have demonstrated that in the reduced form the policy maker has two arguments to consider: the general interest and the interest of special groups (for example capital owners and unions). The interest of the government can follow from electoral support when social welfare is increasing and electoral contributions go with lobbying. For example, in a poor labor-abundant country investors can offer a contribution $\rho$ (where $\rho \leq R$ ) to induce the policy-maker to increase import protection.

The precise weight the policy maker assigns to each group is established by her political support function, as in equation (48).

$$
U(\tau)=\lambda_{1} S W(\tau)+\lambda_{2} \rho(\tau)
$$

where $U$ is the policy-makers utility, where we assumed that the tariff level is the only policy instrument of the government. The weights $\lambda$ characterize the political system (how

\footnotetext{
${ }^{10}$ See for example Helpman (1995) and Grossman and Helpman (2002).
} 
important are the contributions for the electoral campaign) and the policy-makers preferences (how she values reelection against more contributions).

Conditional on the particular values of these weights, she maximizes her utility by the first order condition shown in equation (49).

$$
\frac{\partial U(\tau)}{\partial \tau}=\lambda_{1} \frac{\partial S W(\tau)}{\partial \tau}+\lambda_{2} \frac{\partial \rho(\tau)}{\partial \tau}=0
$$

where $\frac{\partial S W(\tau)}{\partial \tau}$ has been already defined in equations (30) and (31). Since $\rho$ is the fraction of the capital rents $R$ that are assigned to political contributions, the additional term $\frac{\partial \rho(\tau)}{\partial \tau}$ is directly derived from equation (46). Furthermore, $\frac{\partial \rho(\tau)}{\partial \tau}>0$ until the optimum tariff for investors is reached.

The additional element in the political mixture here is the effect of the tariff on social welfare $\left(\frac{\partial S W(\tau)}{\partial \tau}\right)$, which is not known beforehand. The tariff impact on an inequalityadjusted social welfare function can induce changes to the standard results of the political support model. Thus, there is not necessarily a trade-off between both right hand side terms in equation (48) and in some cases they can reinforce each other.

If we analyze small open economies and consider only the social welfare implications, when the distributional effect of the tariff compensates for the efficiency losses we observe a positive optimum tariff rate. From Observation 2, this can be the case only for capital-abundant countries. On the other hand, from Observation 1, in poor countries the distributional and efficiency effects reinforce each other and the socially optimum tariff is zero, though the equilibrium rate may be positive.

When the influence of special interest groups is introduced, the previous partial results can change. In a rich capital-abundant country, the capital-owners have an incentive to lower tariffs, and if the workers can organize, they lobby to increase tariffs. The final outcome depends on the specific rents each group obtains and its political influence. In labor-abundant countries positive tariffs can be explained by the presence of an effective lobby, and in capital rich countries they can be explained by equity concerns that partially overcome free trade lobbying.

These multiple outcomes are summarized in the following observations:

Observation 6 In a Hecksher-Ohlin world, with homogeneous labor owners, concentrated capital and a policy-maker that cares about equity and assigns no weight to political contributions, the government's optimum tariff is higher in small capital-abundant countries than in small labor-abundant countries. 
Observation 7 In a Hecksher-Ohlin capital-abundant economy, with relatively greater inequality aversion, while capital owners will lobby for lower tariffs, the government will be relatively more protectionist because of equity reasons than otherwise. Equity concerns then offset to some extent pressure for lower tariffs in the political marketplace.

Observation 8 In a Hecksher-Ohlin labor-abundant economy, with relatively greater inequality aversion, the government will favor relatively lower tariffs for equity and efficiency reasons, but will be lobbied by capitalists for higher tariffs. Equity concerns then offset to some extent pressure for higher tariffs in the political marketplace.

Basically, when the distributional effects are not significant enough to upset the efficiency losses imposed by the tariff, the common results of the literature emerge and higher tariffs are directly associated to the weight and the contributions of special interest groups. At the same time though, in the presence of distributional concerns rich countries tend to impose higher tariffs than otherwise. Relatively high average tariffs across a subset of capital-rich countries can then be seen as a consequence of inequality considerations by the policymaker, as well as the presence of influential unions. In poor countries positive tariff rates are a direct consequence of the investor lobby overcoming both equity and efficiency concerns. In developing countries with a political system that assigns a significantly higher weight to social welfare than average, tariffs should remain lower than otherwise.

A similar analytical exercise can be carried out with a $2 \times 3$ specific-factors model. In particular, ignoring equity concerns, we have an equilibrium tariff that balances the efficiency effects of the tariff against the interests of owners of sector 1 and sector 2 capital. However, unlike the results for the Heckscher-Ohlin model we developed here, we will not then have unambiguous results when we add inequality to the policy objective mix. This is because, from Observations 4 and 5, the inequality impact of a tariff may itself be ambiguous. If a tariff reduces inequality in the region of the political equilibrium, we would again expect the equity-conscious government to be more protectionist than otherwise. If not, we expect the opposite to hold.

\section{Conclusions}

We have explored theoretical linkages between import protection and the household distribution of income. This complements the existing literature that links trade policy to factor incomes and the functional distribution of income, which is well developed in the literature. 
The main insight of this literature is provided by the Stolper-Samuelson theorem and constitutes a first step in our analysis. In a general equilibrium context, tariff changes ultimately affect the household distribution through variations in ownership patters in conjunction with Stolper-Samuelson effects. To model ownership structures, we used the Heckscher-Ohlin and Ricardo-Viner trade models. Within both frameworks, we are then able to produce theoretical predictions between trade protection, country size, level of development, and personal income inequality.

Another contribution of this paper is that we examine the formal link between social welfare and the equilibrium determinants of the distribution of income. Using Sen-type social welfare functions, we decompose the general equilibrium welfare effects of import protection into real income level and distribution components. The dispersion component is estimated using Gini and Atkinson inequality indexes. With these explicit inequality derivatives we map import protection to inequality-adjusted welfare. In addition, when standard trade models are employed this framework also yields predictions relating social welfare with protection, country size and levels of development. In conjunction with the relevant inequality index, the general form of the decomposition of welfare and inequality we develop here may also be useful in applied general equilibrium applications focused on inequality.

Once the distributional effects of trade liberalization are determined, we can apply endogenous tariff formation models to assess how the optimum tariff is affected by equity concerns. In representative democratic systems, we find that positive optimum tariffs can be sustained in capital-abundant countries even when the policy-maker assigns a low or zero weight to the contributions of special interests groups. In this case, the positive distributional effect of import protection can offset or compensate the efficiency losses of reduced trade. In poor countries, characterized by the relative abundance of labor, positive tariffs are explained by the influence of special interest groups (i.e. capitalists) that heavily lobby for higher tariffs. Thus, import protection in LDCs not only diminishes social welfare through efficiency and equity considerations, but also signals the economic and political weight of the capital-owners. 


\section{References}

[1] Atkinson, A.B. (1970). "On the Measurement of Inequality," Journal of Economic Theory, 2: 244-263.

[2] Barro, R. (2000). "Inequality and Growth in a Panel of Countries," Journal of Economic Growth, 5(1): 5-32.

[3] Bourguignon, F. and C. Morrisson (1989). External Trade and Income Distribution. OECD, Paris.

[4] Bourguignon, F. and C. Morrisson (1990). "Income Distribution, Development and Foreign Trade: A Cross-Sectional Analysis," European Economic Review, 34 (6): 1113-32.

[5] Cline, W.R. (1997). Trade and Income Distribution. Institute for International Economics, Washington D.C.

[6] Dalton, H. (1920). "The Measurement of the Inequality of Incomes," Economic Journal, 30(9): 348-361.

[7] Dixit, A.K. and V. Norman (1980). Theory of International Trade. Cambridge University Press.

[8] Edwards, S. (1997). "Trade Policy, Growth and Income Distribution," American Economic Review, 87 (2): 205-10.

[9] Feenstra, R.C. and G.H. Hanson (2004). "Global Production Sharing and Rising Inequality: A Survey of Trade and Wages," in K. Choi and J. Harrigan eds., Handbook of International Trade, Basil Blackwell: London.

[10] Galor, O. (1994). "Tariffs, Income Distribution and Welfare in a Small OverlappingGenerations Economy," International Economic Review, 35: 173-192.

[11] Grossman, G. and E. Helpman (2002). Interest Groups and Trade Policy. Princeton University Press.

[12] Harsanyi, J.C. (1953). "Cardinal Utility in Welfare Economics and in the Theory of Risk-taking," Journal of Political Economics, 61(5): 434-35.

[13] Harsanyi, J.C. (1955). "Cardinal Welfare, Individualistic Ethics and Interpersonal Comparisons of Utility," Journal of Political Economics, 63(4): 309-21. 
[14] Helpman, E. (1995). "Politics and Trade Policy," NBER Working Paper 5309.

[15] Higgins, M. and J. Williamson (1999). "Explaining Inequality the World Round: Cohort Size, Kuznets Curves and Openness," NBER Working Paper 7224.

[16] Hillman, A.L. (1989). The Political Economy of Protection. Harwood.

[17] Kolm, S. (1969). "The Optimal Production of Social Justice," in Public Economics edited by J. Margolis and H. Guitton. Macmillan.

[18] Lambert, P. (1993). The Distribution and Redistribution of Income. Second ed. Manchester University Press.

[19] Rawls, J. (1971). A Theory of Justice, Belknap Press.

[20] Richardson, J.D. (1995). "Income Inequality and Trade: How to Think, What to Conclude," Journal of Economic Perspectives, 9: 33-35.

[21] Sen, A. K. (1974): "Informational Bases of Alternative Welfare Approaches: Aggregation of Income Distribution," Journal of Public Economics, 3, 387-403.

[22] Sen, A.K. (1976). "Real National Income," Review of Economic Studies, 43: 19-39.

[23] Sen, A.K. (1997). On Economic Inequality. Second ed., Clarendon Press.

[24] Shorrocks, A.F. (1983). "Ranking Income Distributions," Economica, 50: 3-17.

[25] Spilimbergo, A., Londoño J. and M. Székely (1999). "Income Distribution, Factor Endowments, and Trade Openness," Journal of Development Economics, 59: 77-101. 